\title{
Numerical Simulation Research on Flow Characteristics and Influential Factors of Wuxing Lake
}

\author{
Feng Gao ${ }^{1}$, Minquan Feng ${ }^{1 *}$, Shuxian Han $^{2}$ and Jizhong Bai ${ }^{3}$ \\ ${ }^{* 1}$ State Key Laboratory Base of Eco-Hydraulic Engineering in Arid Area (Xi' an University of \\ Technology), Xi'an, 710048, China \\ ${ }^{2}$ The second survey design institute of Hebei Province Water Conservancy and Hydropower, \\ Shijiazhuang, 050000, China \\ ${ }^{3}$ Shanxi Conservancy Technical Institute, Yun Cheng, 044004, China
}

Email: mqfeng@xaut.edu.cn

\begin{abstract}
An accurate simulation on the hydrodynamic force of shallow lakes plays an important role on migration and transformation of lake pollutants and the change rules of lake pollution concentration as well. Based on a twodimensional unstructured shallow-water hydrodynamic model, the paper conducted numerical simulation research on the flow field of Wuxing Lake, and studied profoundly the impact of different wind fields, lake boundaries, inflow \& outflow, and means of inflow \& outflow on the flow field of Wuxing Lake. The results showed that: wind speeds tremendously influence circulation strength of Wuxing Lake, but don't work on circulation patterns; there appear transitive circulation patterns under southeast and northwest steady wind, but the two circulations in this pattern have opposite directions; on contrary, one great and strong circulation appears under the rest directions of wind; the influence of lake boundaries on the change of Wuxing Lake's flow speeds and flow directions is only significant in where the boundaries change, but slight in lake areas that are far away from where boundaries change; inflow \& outflow are only effective in changing water flows in the lake inlet and lake outlet; the difference of inflow means and outflow means exerts certain influence on flow fields in Wuxing Lake, but among them, the fluctuation means help improve the aquatic environment in Wuxing Lake. The research in the paper provides fundamental scientific bases for reconstructing a healthy ecological system of Wuxing Lake.
\end{abstract}

Keywords: Wuxing Lake, Circulation, Numerical simulation, Wind, Boundary.

\section{INTRODUCTION}

Lakes are one of the areas of most frequent human activities. Recently, natural activities and human activities have together damaged the aquatic environment in lakes severely. Problems on lake eutrophication have jeopardized the living quality and sustainable development of residents near lakes in particular. In order to improve present conditions of serious lake pollution, it is a must to figure out hydrodynamic characteristics of lakes and the factors that influence hydrodynamic force of lakes. Therefore, a profound study of hydrodynamic characteristics of lakes is of great scientific significance and of practical application value, which can provide theoretical and technological bases for lake aquatic environment management and lake water quality improvement [1].

Considering that shallow lake hydrodynamic force is uneven in spatial distribution and that shallow lake flows are small, it is difficult to use practical simultaneous observation to study lake hydrodynamic force. Instead, numerical simulation is used for such study [2-4]. So far, many mathematical model had established [5-11]. Liu Xufeng et al.
[1] established a two-dimensional shallow-water hydrodynamic model to analyze primarily flow states of the wind-driven circulations in Taihu Lake, and undertook numerical simulation research on the distribution characteristics and rules of Taihu Lake hydrodynamic force under different wind conditions as well; $\mathrm{Hu}$ Weiping et al. [12-14] performed a three-dimensional numerical simulation on the hydrodynamic force in Taihu Lake, and also studied wind-driven circulations in Taihu Lake in terms of positive and negative storm surges, typical wind fields, and reclamation in the Mashan district; Han Hongjuan et al. [15] compared the structural differences between stratified flow fields and vertically average flow fields of Zhuhu Lake under the winds of different speeds, obtained the critical value of wind speeds that were jointly influenced by wind fields and inflow \& outflow, and turned out to find that the critical value was dominated mainly by wind directions and inflow \& outflow; Han Hongjuan et al. [16] researched on the influence of inflow \& outflow on the structure of Zhuhu Lake's flow fields as well. Existing research focuses on how lake circulations are influenced by wind speeds, wind directions, and changes of Lake Bottom landform. Despite public 
acceptance that lake boundaries impact on lake circulations to a certain degree, but the lack of quantitative research and exceptional changes of lake boundaries render relative research infrequent. There are less frequent reports on the comprehensive influence on lake flow fields by wind fields, inflows means and outflow means, inflow \& outflow, and lake boundaries. Given that, and by integrating previous studies, the paper designed numerous operating conditions for numerical experiments, established a two-dimensional unstructured shallow-water hydrodynamic model for Wuxing Lake, and performed numerical simulation research on the lake circulations under different wind fields, landforms, inflows means and outflow means, inflow \& outflow, and lake boundaries as well. Circulation characteristics and influential factors of Wuxing Lake also underwent research, providing bases and foundation for further treatment on the hydrodynamic force of Wuxing Lake.

\section{THEORY AND METHOD}

\subsection{Model construction}

The depth of Wuxing Lake is about $1-2 \mathrm{~m}$, the horizontal scale is much larger than the vertical scale of movement, Therefore, established a two-dimensional flow model under unstructured triangular mesh, arbitrary triangle is a computing unit, and using cell center finite volume method to solve the equation, in vertical uses coordinate conversion and orthogonal curvilinear coordinates horizontal. Time integration utilize finite-difference of second order accuracy and external mode splitting technique. To avoid numerical oscillations use the limiter function of second order TVD format.

Equation of continuity of flow:

$$
\frac{\partial Z}{\partial \mathrm{t}}+\frac{\partial(h u)}{\partial x}+\frac{\partial(h \mathrm{v})}{\partial y}=0
$$

where $\mathrm{Z}$ is a water level at the $\mathrm{x}, \mathrm{y}, \mathrm{m}$; $\mathrm{h}$ is the water depth at the $\mathrm{x}, \mathrm{y}, \mathrm{m}$; $\mathrm{u}$ is the $\mathrm{x}$-direction velocity component, $\mathrm{m} / \mathrm{s}$; $\mathrm{v}$ is the $y$-direction velocity component, $\mathrm{m} / \mathrm{s}$; $\mathrm{t}$ is the time, $\mathrm{s} ; \mathrm{x}$ is the transverse spatial coordinate, $\mathrm{m}$; $\mathrm{y}$ coordinates for vertical space, $\mathrm{m}$.

Water movement equation:

$$
\frac{\partial u}{\partial t}+\frac{\partial u^{2}}{\partial x}+\frac{\partial v u}{\partial y}=f v-g \frac{\partial \eta}{\partial x}-\frac{1}{\rho_{0}} \frac{\partial p_{a}}{\partial x}-\frac{1}{\rho_{0} h}\left(\frac{\partial s_{x x}}{\partial x}+\frac{\partial s_{x y}}{\partial y}\right)
$$

$+F_{u}+u_{S} S$

$\frac{\partial v}{\partial t}+\frac{\partial v^{2}}{\partial y}+\frac{\partial u v}{\partial x}=-f u-g \frac{\partial \eta}{\partial y}-\frac{1}{\rho_{0}} \frac{\partial p_{a}}{\partial y}-\frac{1}{\rho_{0} h}\left(\frac{\partial s_{y x}}{\partial x}+\frac{\partial s_{y y}}{\partial y}\right)$

$+F_{v}+v_{S} S$

where $\mathrm{g}$ is the acceleration of gravity, $\mathrm{m} / \mathrm{s}^{2} ; \mathrm{nz}$ is the Manning coefficient; $\mathrm{fv}$, fu is the Coriolis acceleration term; $\frac{1}{\rho_{0}} \frac{\partial p_{a}}{\partial x}, \frac{1}{\rho_{0}} \frac{\partial p_{a}}{\partial y}$ is the Surface water level acceleration term; $\frac{1}{\rho_{0}} \frac{\partial p_{a}}{\partial x}, \frac{1}{\rho_{0}} \frac{\partial p_{a}}{\partial y}$ is the Atmospheric pressure gradient; $\frac{1}{\rho_{0} h}\left(\frac{\partial s_{x x}}{\partial x}+\frac{\partial s_{x y}}{\partial y}\right), \frac{1}{\rho_{0} h}\left(\frac{\partial s_{y x}}{\partial x}+\frac{\partial s_{y y}}{\partial y}\right)$ is the Wave radiation stress terms; Fu, Fv is the Horizontal eddy viscosity term; usS, vsS is the source term inflow generated acceleration term, the remaining consistent with the formula (2.1). [17-20]

\section{2 model configuration}

The whole Wuxing Lake was only studied for the influence of lake boundaries on Wuxing Lake flow fields. The north lake of Wuxing Lake served as the objective for the rest studies. Wuxing Lake is a shallow lake with small areas and irregular shapes. Unstructured grids [11, 21-23] were used here to fit the complicated lake boundaries better. There were altogether 1213 grids of an average size of $10 \mathrm{~m} \times 10 \mathrm{~m}$ and 765 grid nodes. The largest grid was $1100 \mathrm{~m}^{2}$, and the smallest $26 \mathrm{~m}^{2}$.the grid is smaller and the result is more accurate, therefore in order to ensure the accuracy of the calculation results, the grid size is different at different regions. Grid partition was shown in Figure 1. With inverse distance weighted methods, the lake bottom landform was interpolated to each of the grid node. To fit landform change against lake boundaries better, the network grids near lake boundaries were intensified. The subsequently obtained landform map was shown in Figure 2. The value of the initial water level upon operating the model was set as Height $346 \mathrm{~m}$, an approximate value to the real one, and the initial flow speed was set as $0 \mathrm{~m} / \mathrm{s}$.

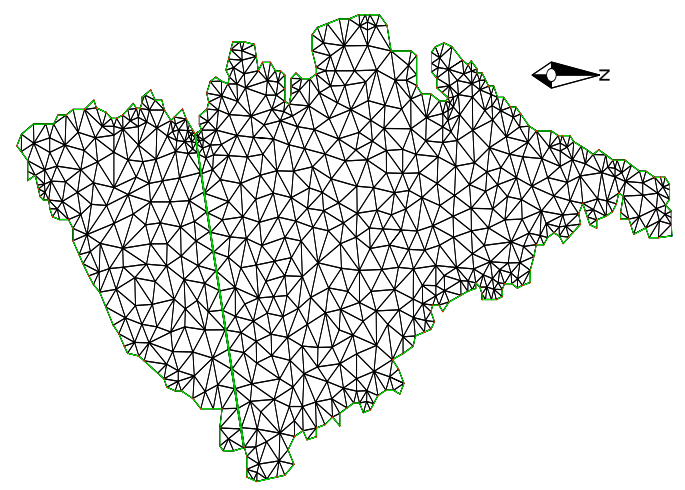

Figure 1. The computation grid of Wuxing Lake

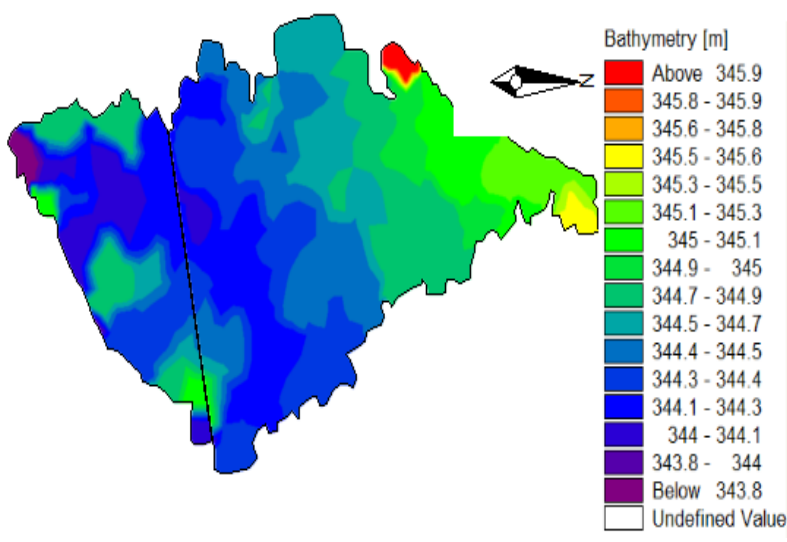

Figure 2. The terrain of Wuxing Lake 


\subsection{Model verification}

As the greatest freshwater lake in Shanxi province though, there are no vital research data records on the lake's hydrology, environment, ecology or biology. Since March, 2015, the research group has undertaken monthly on-site measurement on its stage hydrograph. Figure 3 showed the comparison between the simulative value and the real value of Wuxing Lake's stage hydrograph. Their high degree of fitting verified the applicability of the model proposed in the paper to Wuxing Lake to a certain extent.

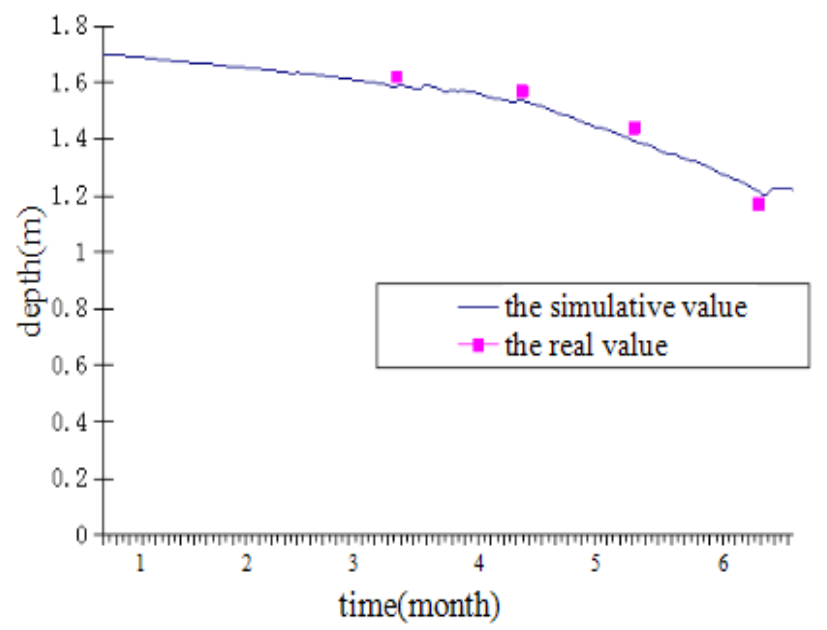

Figure 3. The comparison between the simulative value and the real value of Wuxing Lake's stage hydrograph

\section{NUMERICAL EXPERIMENT ON CIRCULATION CHARACTERISTICS OF WUXING LAKE}

\subsection{Operating condition setting}

Considering the importance of wind fields' influence on shallow lake flow field, the paper derived data of wind fields from daily sequence data from 2009 to 2015 in Yongji city. According to statistics on Wuxing Lake, northwest wind prevails in winter lake, and southeast wind prevails in summer lake. To compare the influence of different wind fields on Wuxing Lake circulations, the paper also researched on the influence of north wind on Wuxing Lake flow fields. Sewage treatment plants are under construction in upstream Wuxing Lake, with the discharge capacity of $60000 \mathrm{~m}^{3} / \mathrm{s}$. As the daily flow amount of Sushui river exceeds $60000 \mathrm{~m}^{3} / \mathrm{s}$ for recent years, the future inflow amount of Wuxing Lake from Sushui river can be determined as $60000 \mathrm{~m}^{3} / \mathrm{s}$. Sushui River will only flow into Wuxing Lake in future (until the construction work is completed), thus the inflow means still remains uncertain. Based on the most likely means, three operating conditions were designed to research the influence of lake boundaries on Wuxing Lake flow fields. Seven numerical experiments were designed in the paper as shown in Table 1, where the influence of different wind speeds, wind directions, runoffs, lake boundaries, inflow means on Wuxing Lake flow fields were researched by 1 and 2, 2 and 3, 4 and 7, 3 and 5, and 6, 8 and 9, respectively.
Table 1. Designed conditions in the numerical experiments

\begin{tabular}{|c|c|}
\hline Conditions & Calculation condition \\
\hline 1 & $\begin{array}{l}\text { southeaster + wind velocity } 6 \mathrm{~m} / \mathrm{s}+\text { real topography } \\
+ \text { current lakeshore boundary }\end{array}$ \\
\hline 2 & $\begin{array}{l}\text { southeaster }+ \text { wind velocity } 10 \mathrm{~m} / \mathrm{s}+\text { real topography } \\
+ \text { current lakeshore boundary }\end{array}$ \\
\hline 3 & $\begin{array}{l}\text { boreas + wind velocity } 10 \mathrm{~m} / \mathrm{s}+\text { real topography } \\
+ \text { current lakeshore boundary }\end{array}$ \\
\hline 4 & $\begin{array}{l}\text { boreas }+ \text { wind velocity } 10 \mathrm{~m} / \mathrm{s}+\text { steady runoff into } \\
\text { the lake } \\
1.39 \mathrm{~m}^{3} / \mathrm{s}+\text { real topography }+ \text { current lakeshore } \\
\text { boundary }\end{array}$ \\
\hline 5 & boreas + wind velocity $10 \mathrm{~m} / \mathrm{s}+$ runoff $0 \mathrm{~m}^{3} / \mathrm{s}+$ real \\
\hline 6 & $\begin{array}{l}\text { boreas }+ \text { wind velocity } 10 \mathrm{~m} / \mathrm{s}+\text { runoff } 0 \mathrm{~m}^{3} / \mathrm{s}+\text { real } \\
\text { topography }+ \text { completely Unicom lakeshore } \\
\text { boundary }\end{array}$ \\
\hline 7 & $\begin{array}{l}\text { boreas }+ \text { wind velocity } 10 / \mathrm{s}+\text { steady runoff into the } \\
\text { lake } 0.69 \mathrm{~m}^{3} / \mathrm{s}+\text { real topography }+ \text { current lakeshore } \\
\text { boundary }\end{array}$ \\
\hline 8 & $\begin{array}{l}\text { calm }+ \text { steady runoff into the lake } 1.39 \mathrm{~m}^{3} / \mathrm{s}+\text { real } \\
\text { topography }+ \text { current lakeshore boundary }\end{array}$ \\
\hline 9 & $\begin{array}{l}\text { calm + undulated runoff into the lake } 1.39 \mathrm{~m}^{3} / \mathrm{s} \\
+ \text { real topography }+ \text { current lakeshore boundary }\end{array}$ \\
\hline
\end{tabular}

\subsection{Analysis of the influence of wind speeds on flow fields}

The currently closed Wuxing Lake has a slow flow driven by wind. However, it is hard to simultaneously access the real data of wind fields and that of lake flow fields. Thus, the typical wind field (southeast wind) was used instead for simulative research on Wuxing Lake flow fields in the paper. To compare the influence of different wind speeds on Wuxing Lake flow fields, this section showcased the lake flow distribution structure at the southeast wind blowing at $6 \mathrm{~m} / \mathrm{s}$ and $10 \mathrm{~m} / \mathrm{s}$, respectively. Figure 4 (a) and Figure 4 (b) showed the numerical simulative distribution diagrams of flow fields at the southeast wind speed of $6 \mathrm{~m} / \mathrm{s}$ and $10 \mathrm{~m} / \mathrm{s}$, respectively.

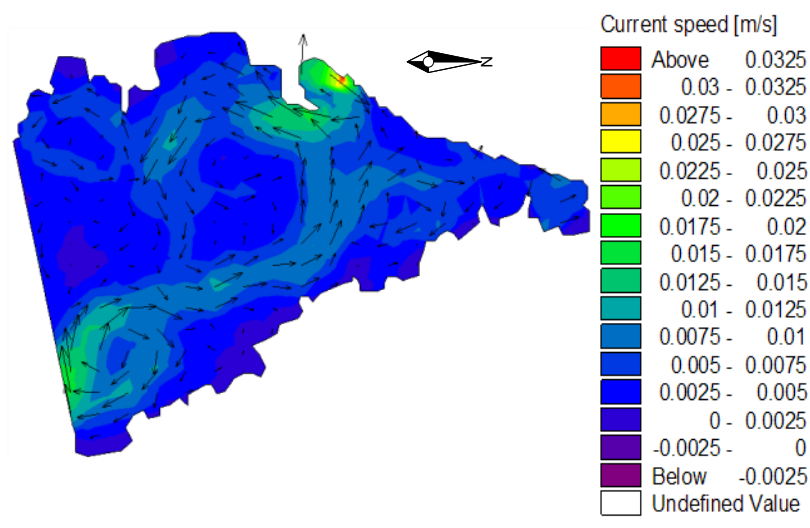

(a) 


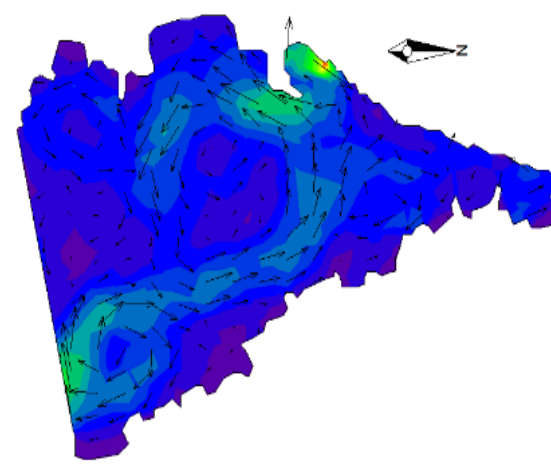

Current speed $[\mathrm{m} / \mathrm{s}]$

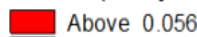
$0.052-0.056$ $0.048-0.052$ $0.044-0.048$ $\square .04-0.044$
$\square .036-0.04$ $\square$
$\square .036-0.04$
$0.032-0.036$ $0.028-0.032$ $0.024-0.028$ $0.02-0.024$ $0.016-0.02$ $0.012-0.016$

$0.008-0.012$ $0.004-0.008$ $0-0.004$ Below 0

(b)

Figure 4.Flow distribution structure at the southeast wind speed of $6 \mathrm{~m} / \mathrm{s}$ and $10 \mathrm{~m} / \mathrm{s}$, respectively

As can be seen from the above results, under the continuous action of steady southeast wind, there emerge great differences among flow speeds at different areas in Wuxing Lake. Specifically, the nearshore flow speeds were far above offshore flow speeds or central ones. Flow speeds were higher at northwest lake and at southeast lake than those at any other directions. Wuxing Lake flow speeds witnessed remarkable differences at $10 \mathrm{~m} / \mathrm{s}$ wind and at $6 \mathrm{~m} / \mathrm{s}$ wind. At $10 \mathrm{~m} / \mathrm{s}$ wind, the highest flow speed was about $5.6 \mathrm{~cm} / \mathrm{s}$, and the central and offshore flow speeds were between 0.8 $1.6 \mathrm{~cm} / \mathrm{s}$; while at $6 \mathrm{~m} / \mathrm{s}$ wind, the highest flow speed dropped by $2.4 \mathrm{~cm} / \mathrm{s}$ from the original $5.6 \mathrm{~cm} / \mathrm{s}$, and the central and offshore flow speeds decreased to between $0.2-0.75 \mathrm{~cm} / \mathrm{s}$. Differences of wind speeds exerted no influence on lake circulation structures basically, as four circulations with various sizes appeared both at $10 \mathrm{~m} / \mathrm{s}$ wind and at $6 \mathrm{~m} / \mathrm{s}$ wind. There was the biggest anticlockwise circulation in central lake, and a smaller one in southwest lake; while clockwise circulations appeared both in southeast lake and north lake, smaller than the one in central lake. Surely other smaller circulations appeared in other lake areas, and the author will not list them one by one for the small sizes.

\subsection{Analysis of wind directions on flow fields}

By studying the influence of different wind speeds on flow fields in section 3.2, we found that the influence of different wind speeds was insignificant on flow field structures, but significant on flow speeds. Previous studies showed that under different wind directions, the flow types of flow fields remained unchanged basically, but circulation directions were opposite. There are still research gaps in how difference wind directions influence lake flow speeds. Thus, we designed research on changes of flow field structures, flow speeds and flow directions of Wuxing Lake at $10 \mathrm{~m} / \mathrm{s}$ wind under different wind directions (northwest wind, north wind, southwest wind).

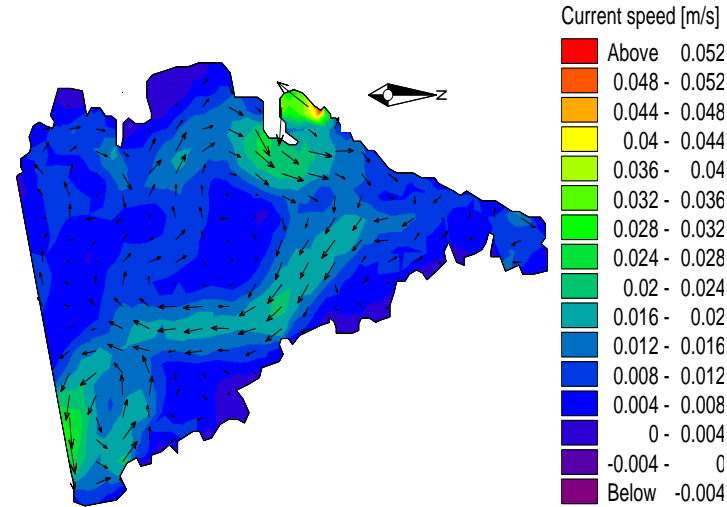

(a)

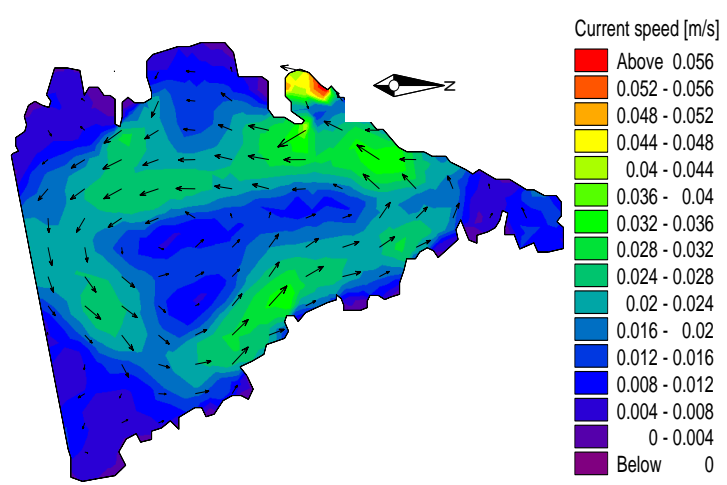

(b)

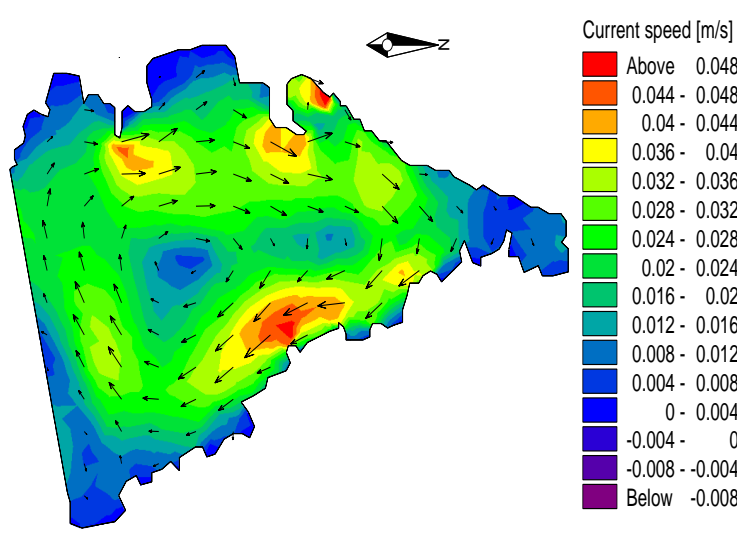

(c)

Figure 5. (a) (b) (c) are flow field distribution diagrams of Wuxing Lake at $10 \mathrm{~m} / \mathrm{s}$ wind under different wind directions (northwest wind, north wind, southwest wind)

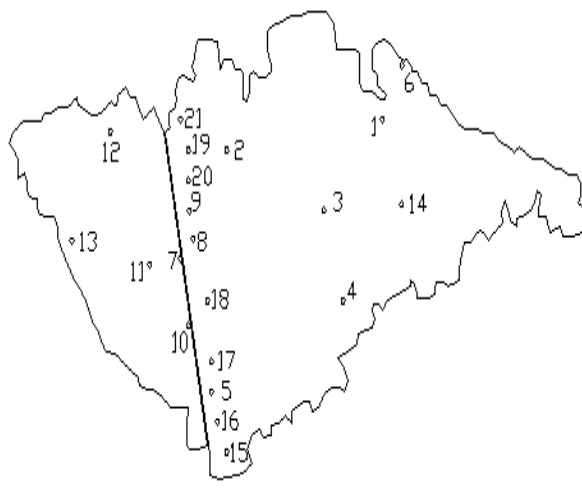

Figure 6. Shows the positions chosen for comparison of flow speeds 
Through comparison between Figure 4 (b) and Figure 5 (a), under the influence of equal and opposite steady winds, there emerge opposite circulations at different sizes and with almost the same circulation structures, intensities and flow types. Southeast wind prevails in summer Wuxing Lake, when the main circulation in central lake is anticlockwise; while under northwest wind in winter Wuxing Lake, the main circulation in central lake is clockwise, but with basically equal flow speeds.

To expound flow field characteristics of Wuxing Lake under other wind directions, Figure 5 (b) and 5 (c) show the flow field distribution at the north wind and southwest wind blowing at $10 \mathrm{~m} / \mathrm{s}$, respectively. Under them, each great and strong circulation emerged in Wuxing Lake, one being anticlockwise and another being clockwise; at this time, the flow speed was about $0.8 \mathrm{~cm} / \mathrm{s}$ at central lake and $2.2-4.3 \mathrm{~cm} / \mathrm{s}$ at nearshore stretches. Compared to Figure 4 (b), significant changes happen to both the structures, intensities and flow types of the flow fields in Wuxing Lake under north wind and under southwest wind. The highest flow speed under north wind was $5.4 \mathrm{~cm} / \mathrm{s}$ in northwest lake, similar to the number of $6.2 \mathrm{~cm} / \mathrm{s}$ at southwest wind. However, the flow speed at southeast lake had lowered down much. Flow speeds in most of the other positions had changed remarkably as well. Table 2 shows the flow speeds at different positions (Figure 6) in the lake. This shows that wind directions not only impact on lake circulation directions and formation of circulation structures greatly, but also influence lake flow speeds to a certain degree.

Table 2. Comparison of flow speeds at different positions $(\mathrm{cm} / \mathrm{s})$

\begin{tabular}{lllll}
\hline Position & $\begin{array}{l}\text { Velocity of } \\
\text { northwester }\end{array}$ & $\begin{array}{l}\text { Velocity } \\
\text { of boreas }\end{array}$ & $\begin{array}{l}\text { Velocity of } \\
\text { southeaster }\end{array}$ & $\begin{array}{l}\text { Velocity of } \\
\text { northeaster }\end{array}$ \\
\hline 1 & 2.3 & 3.38 & 2.29 & 5.4 \\
2 & 0.68 & 2.21 & 0.70 & 3.01 \\
3 & 0.46 & 1.13 & 0.46 & 1.71 \\
4 & 1.46 & 2.87 & 1.42 & 3.92 \\
5 & 2.59 & 0.64 & 2.51 & 1.23 \\
6 & 4.94 & 5.53 & 4.93 & 3.34 \\
\hline
\end{tabular}

\section{4 analysis of lake boundaries on flow fields}

By effecting on water level change, flow field circulation structures, and flow field circulation characteristics, lake boundaries in Wuxing Lake influence expansion and transport of lake substances, the aquatic environment quality, and ecological system as well. Current studies of how circulation characteristics are influenced by lake boundaries remain mostly qualitative. Quantitative studies are concentrated on how lake bottom landforms instead of lake boundaries influence lake flow field characteristics. The main reason is that although most lakes' boundaries change little, Wuxing Lake has been developed into north lake and south lake due to various reasons; it is inevitable that the two parts of lakes will connect to Sushui Lake, thus the change of lake boundaries for Wuxing Lake can be realized in reality. The paper sets up three operation conditions to analyze how lake boundaries change influence flow fields of Wuxing Lake.

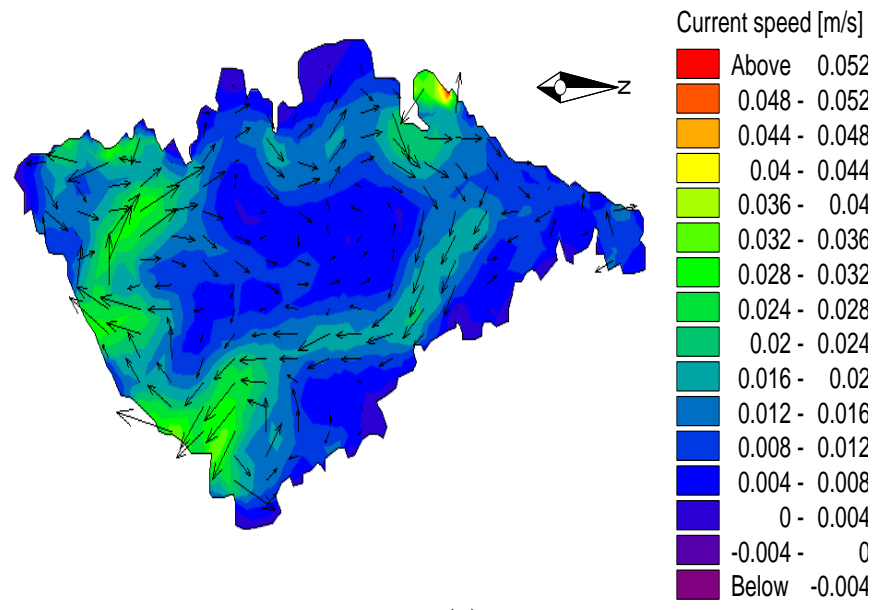

(a)

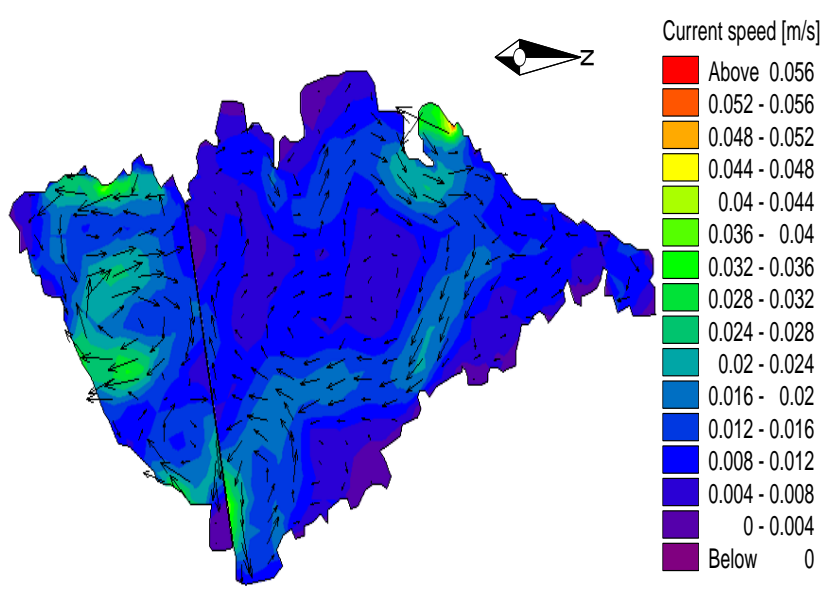

(b)

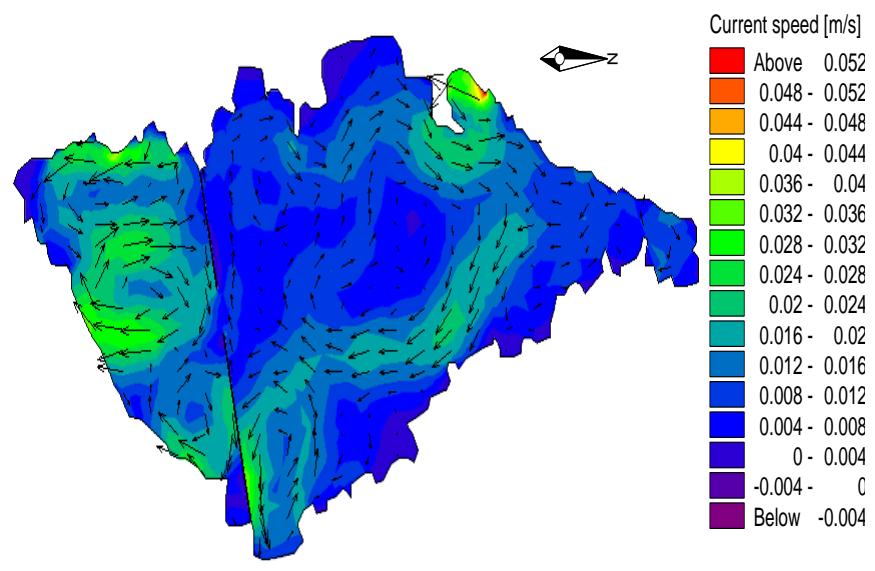

(c)

Figure 7. The flow field distribution diagrams when north lake totally connects to south lake, when north lake is isolated from south lake, and when north lake connects partly to south lake, respectively

According to Figure 7, the change of lake boundaries exerts great significance on flow fields. In Figure 7 (a) when north lake totally connects to south lake, a large and strong clockwise circulation emerges in the lake, and some compensatory anticlockwise small circulations emerge in southwest lake, northwest lake, east lake and north lake. After north lake was isolated from south lake, there appeared three circulations with different sizes in south lake: the lower one was weak and clockwise, the upper one flat and anticlockwise, and the middle one anticlockwise; as a 
contrast, circulations in north lake were the same with what appeared in Figure 7 (a). The overall flow speed of south lake had dropped greatly. Circulation intensity in south lake had been weakened, especially for circulations in middle and lower south lake, which failed to be strengthened but turned out to be weakened as the water flow from north to south in north lake was blocked by lake boundaries. Meanwhile, due to blockage of lake boundaries, the water flow from south to north at upper south lake also failed to strengthen circulations at middle and lower parts of south lake, but lowered the circulation intensity at middle and lower parts of south lake instead. The weakened water flow in north lake after smashing into lake boundaries entailed its flow speed to drop and its flow direction to change, thus the circulation intensities in north lake were reduced. Because of limited isolation ranges, circulation structures and scales in north lake areas far from the isolation positions were influenced insignificantly; however, the south lake was small in itself, so it was remarkably affected by the isolation. Considering actual conditions, the realization of complete connection of north lake to south lake may cost enormous manpower and material resources, thus it is considerable to partly connect them (Figure 7 (c)). When partly connected, it can be found from Figure 7 (c) a great flow change in the connected areas. The convergence of water flows from south to north in north lake and water flows from north to south in south lake helped reduce flow speed greatly in connected areas. The convergence didn't change circulation structures of the two parts of Wuxing Lake, but intensified circulations. North lake flows below connected areas changed directions due to flow blockage in connected areas, part of which entered south lake to have intensified circulations in lower south lake, and the rest of which continued their way down to have intensified circulation in lower north lake; under the power of water flow in connected areas, south lake flows above connected areas entered north lake and maintained the flow of large circulations in north lake. However, flow speeds of water far away from connected areas (northern north lake, southern south lake, etc.) remained unchanged basically. The following table shows comparison of flow speeds at different positions under three kinds of lake boundaries.

Table 3. Comparison of flow speeds at different positions under three kinds of lake boundaries $(\mathrm{cm} / \mathrm{s})$

\begin{tabular}{llll}
\hline Position & Part abruption & $\begin{array}{l}\text { Completely } \\
\text { abruption }\end{array}$ & $\begin{array}{l}\text { Completely } \\
\text { unicom }\end{array}$ \\
\hline 7 & 0.741 & 1.08 & 0.687 \\
8 & 0.092 & 1.24 & 0.975 \\
9 & 1.2 & 1.14 & 1.18 \\
10 & 2.02 & 1.62 & 1.59 \\
11 & 1.95 & 1.73 & 1.63 \\
12 & 2.01 & 2.12 & 1.99 \\
13 & 2.36 & 2.2 & 1.89 \\
14 & 1.75 & 1.72 & 1.69 \\
\hline
\end{tabular}

\section{4 analysis of the influence of inflow amounts on flow} fields

Inflow \& outflow constitute one of the main forms of lake movement. As current water quality in both lakes and reservoirs has been seriously deteriorated, ecological water division is regarded as an important means to improve water quality in lakes. It is therefore vital to figure out properly how inflow \& outflow change influences lake flow fields, which is in turn of great significance to determine the quantity of ecological water division.

To research on the impact of inflow \& outflow on flow structures of Wuxing Lake, the section designed flow field distribution of Wuxing Lake under different flow volumes at the southeast wind blowing at $6 \mathrm{~m} / \mathrm{s}$, and the impact of inflow means and outflow means on flow fields in Wuxing Lake under calm wind as well. Allowing for practical conditions, the lake inlet was preliminarily set at southeast Wuxing Lake with the flow speed of $1.39 \mathrm{~m} 3 / \mathrm{s}$; and the lake outlet at southwest Wuxing Lake. The model ran the total of 5000 steps at the time step of 30 s. It reached the steady state at around the 4000th step. Figure 8 (a) and (b) are flow field distribution diagrams of Wuxing Lake at $1.39 \mathrm{~m}^{3} / \mathrm{s}$ and $0.69 \mathrm{~m}^{3} / \mathrm{s}$, respectively.

Compared Figure 8 (a) and (b) to Figure 5 (a), it can be seen that flow fields at areas far away from the inlet and outlet remain unchanged fundamentally; southeast circulations deviate to northwest directions; circulations near the outlet at the flow speed of $1.39 \mathrm{~m}^{3} / \mathrm{s}$ disappear; circulations near the outlet at the flow speed of $0.69 \mathrm{~m}^{3} / \mathrm{s}$ continue to exist, but with a decreasing intensity. Overall, the impact of inflow \& outflow on flow structures of Wuxing Lake is weak. The impact of inflow \& outflow on flow speeds of Wuxing Lake was great in only areas near the south bank of north lake, and the scope of influence was closely connected with inflow volumes. Table 4 shows comparison of flow speeds. Flow directions of the circulations near the inlet and outlet agreed with those of inflow \& outflow, thus increasing the flow speeds in these areas at various degrees. Flows in areas near south boundaries of Wuxing Lake were primarily driven by inflow \& outflow instead of the local weak wind power, thus flow speed changes were great. The flow speed in the eastern part of the outlet dropped at the flow speed of $0.69 \mathrm{~m}^{3} / \mathrm{s}$, but was higher at the flow speed of $1.39 \mathrm{~m}^{3} / \mathrm{s}$. The main reason was that circulations in this area at the flow speed of $0.69 \mathrm{~m}^{3} / \mathrm{s}$ were weakened due to the opposite directions of inflow \& outflow and circulations in this area; while flow speeds in this area at the flow speed of $1.39 \mathrm{~m}^{3} / \mathrm{s}$ increased since they were determined primarily by inflow \& outflow, whose intensity overpowered wind-driven circulations which disappeared as a result.

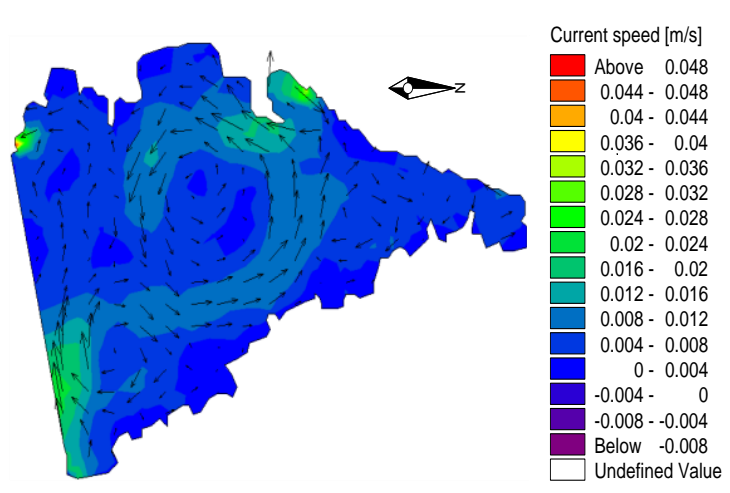

(a) 


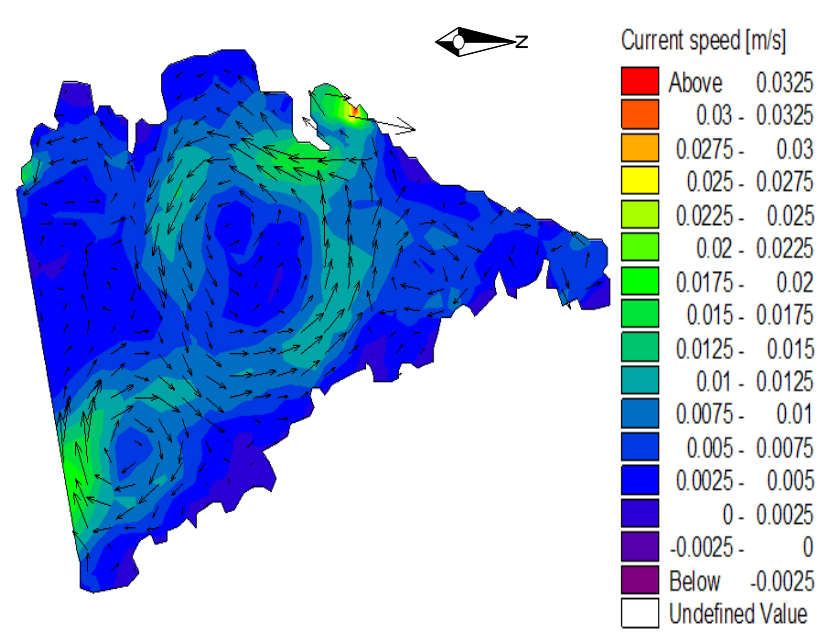

(b)

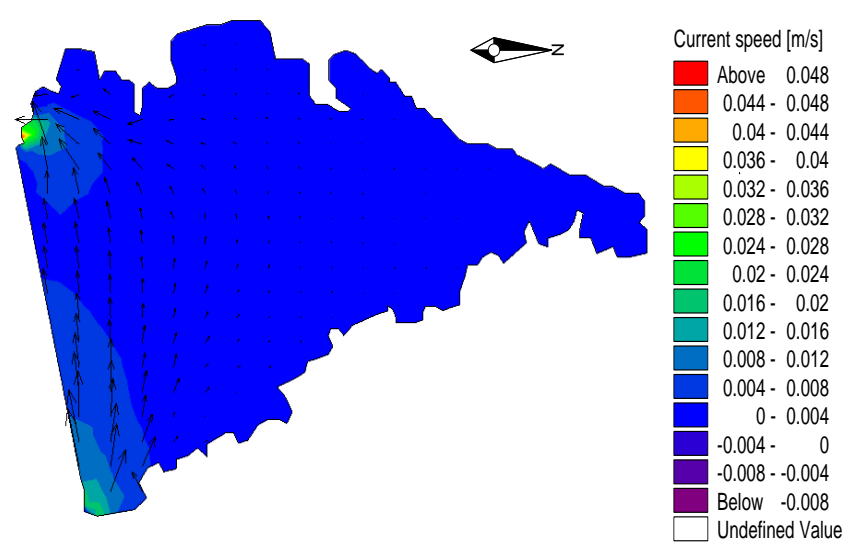

(c)

Figure 8. Flow field distribution diagrams with different flow volumes in Wuxing Lake under wind or under calm wind

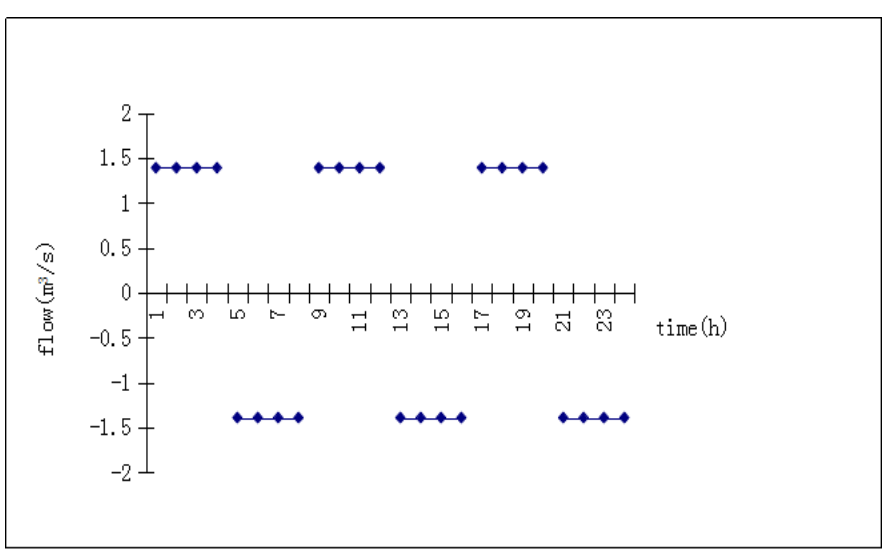

Figure 9. The process of flow volume entering Wuxing Lake or exiting Wuxing Lake

Under calm wind, flow fields of Wuxing Lake were determined merely by inflow \& outflow. As seen from Figure 8 (c), the flow states changed greatly only at the inlet and the outlet, but remained unchanged in areas far away from the inlet or the outlet. Given that actual low winds blow Wuxing Lake for some days annually, if such steady inflow means is still used for these days, the water flow of Wuxing Lake will slow down, and the water replacement is time-consuming as well. It is unfavorable for improvement of the aquatic environment in Wuxing Lake, thus it is necessary to design the inflow means. The paper designed that the inflow \& outflow ran at $1.39 \mathrm{~m}^{3} / \mathrm{s}$ with the cycle of $4 \mathrm{~h}$. Figure 9 shows the specific process of flow volume entering Wuxing Lake or exiting Wuxing Lake. Compared Figure 8 (c) with Figure 10 (a) and (b), it can be seen that inflow means exert great significance on flow fields of Wuxing Lake. With the fluctuation means, higher-quality inflows mix with the lake better to dilute the lake at full extents, meaningful to improve aquatic environment in Wuxing Lake.

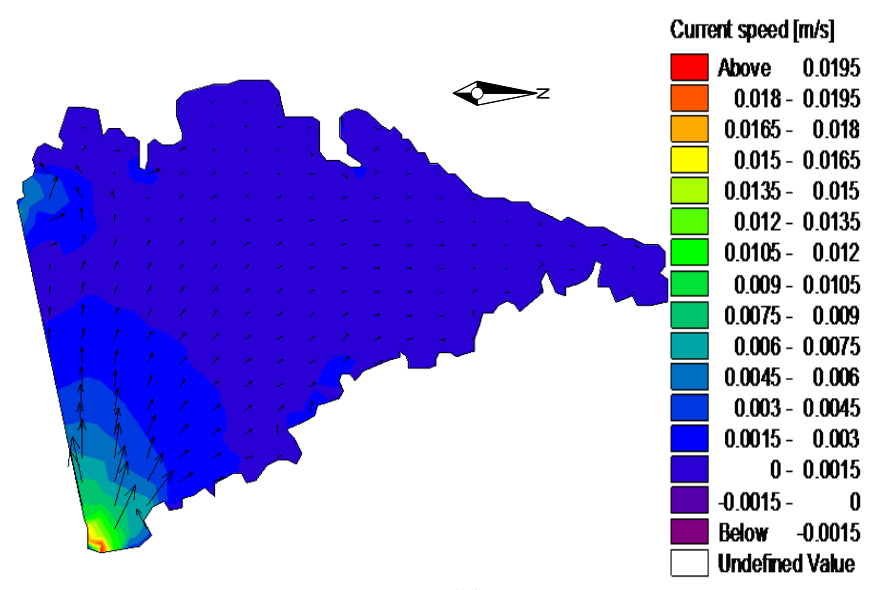

(a)

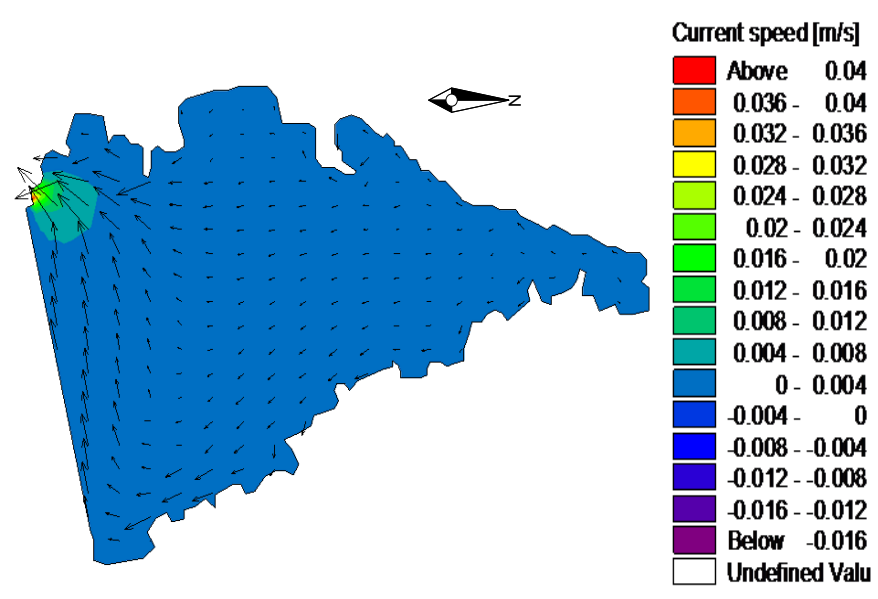

(b)

Figure 10. Flow field distribution diagram at the fluctuation means of inflow \& outflow

Table 4. Comparison of flow speeds at various positions with different inflow volumes and outflow volumes $(\mathrm{cm} / \mathrm{s})$

\begin{tabular}{llll}
\hline Position & $\begin{array}{l}\text { Velocity in } \\
1.39 \mathrm{~m}^{3} / \mathrm{s}\end{array}$ & $\begin{array}{l}\text { Velocity in } \\
0.69 \mathrm{~m}^{3} / \mathrm{s}\end{array}$ & $\begin{array}{l}\text { Velocity in } \\
0 \mathrm{~m}^{3} / \mathrm{s}\end{array}$ \\
\hline 15 & 0.98 & 0.41 & 0.43 \\
16 & 1.52 & 1.19 & 1.16 \\
17 & 1.87 & 1.27 & 1.62 \\
18 & 1.01 & 0.32 & 0.68 \\
19 & 0.58 & 0.57 & 0.45 \\
20 & 0.46 & 0.38 & 0.34 \\
21 & 1.95 & 0.54 & 0.99 \\
\hline
\end{tabular}




\section{CONCLUSION}

The paper establishes a two-dimensional unstructured shallow-water hydrodynamic model for numerical simulation research on how different wind speeds, wind directions, inflow runoffs, lake bottom landforms, and lake boundaries influence on lake fields in Wuxing Lake. The research results show that:

(1) Wind is one of the most influential factors on lake fields in Wuxing Lake. The wind speeds are closely connected with lake flow speeds, but influence lake flow structures slightly; the circulations under opposite wind directions and same wind speeds share similar sizes and opposite directions; compared with different wind directions, it can be found that Wuxing Lake circulations are alternatively clockwise, anticlockwise and transitional.

(2) According to quantitative research on the influence of lake boundaries on Wuxing Lake flow fields, the influential zones appear mostly near where lake boundaries change, but flow fields change little in lake areas that are far away from where lake boundaries change.

(3) The inflow volume and outflow volume at the lake inlet and lake outlet merely have certain effects on flow areas near the lake inlet and lake outlet, and the scope of effects is related with the size of the flow volumes. Under calm wind, flow fields of Wuxing Lake were determined merely by inflow \& outflow. The influence of inflow \& outflow is insignificance for lake flows in areas far away from the inlet and outlet. In spite of slight impact on flow fields in Wuxing Lake, the fluctuation means is meaningful to improving the aquatic environment in Wuxing Lake. It is important for the Wuxing lake aquatic environment management and water quality improvement

\section{ACKNOWLEDGMENT}

This research is supported by Shanxi Province Research and Extension Project of hydro science and Technology (201413); the Specialized Research Fund for the Doctoral Program of Higher Education of China (20126118110015); Science and Technology Innovation Project of Shaanxi Province in China under Grant (2013SZS02-Z01).

\section{REFERENCES}

[1] Xu-feng, LIU and Qing-quan, "Numerical study on the characteristics of wind-induced current in Taihu Lake," Chinese Journal of Hydrodynamics, vol. 24, no. 4, pp. 512-518, 2009.

[2] LUO Lian-cong and QIN Bo-qiang, "Numerical simulation based on a three-dimensional shallow-water hydrodynamic model in Lake Taihu-Current circulations in Lake Taihu with prevailing windforcing," Chinese Journal of Hydrodynamics, vol. 18, no. 6, pp. 686-691, 2003

[3] Han Long-Xi, Long Dong-Yan, Li Hong-Jing, Zhang De-Min and Zhang Peng, "3D numerical modeling of wind-driven flow in the high salinity Aibi Lake," Advances in Water Science, vol. 22, no. 1, pp. 97-103, 2011. DOI: CNKI: 32-1309/P.20110115.2236.008.

[4] Lei Zhao, Xiaoling Zhang, Yong Liu, Bin He, Xiang Zhu, Rui Zou and Yuanguan Zhu, "Three-dimensional hydrodynamic and water quality model for TMDL development of Lake Fuxian, China," Journal of Environmental Sciences, vol. 24, no. 8, pp. 228-243, 2013. DOI: $10.1016 /$ j.jhydrol.2013.03.049.

[5] Asmar B. N. and Peter Ergenzinger, "Dynamic simulation of the Dead Sea," Advances in Water Resources, vol. 25, pp. 263-277, 2002. DOI: 10.1016/S0309-1708 (01)00063-X.

[6] Victory Podsetchine and Gerald Schernewski, "The influence of spatial wind inhomogeneity on flow patterns in small lake," Wat. Res., vol. 33, no. 15, pp. 3348-3359, 1999. DOI: $\underline{10.1016 / \mathrm{S} 0043-1354}$ (99)00035-4.

[7] BorisV Chubarenko, Yongqi Wang and Irina $P$ Chubarenko, "Wind-driven current simulations around the Island Mainau (Lake constance)," Ecological Modeling, vol. 138, pp. 55-73, 2001. DOI: 10.1016/S0304-3800 (00)00393-8.

[8] Yuan-ying CHEN and Qing-quan LIU, "Numerical study of hydrodynamic process in Chaohu Lake," Journal of Hydrodynamics, vol. 27, no. 5, pp. 720729, 2015. DOI: $10.1016 /$ S1001-6058 (15)60534-0.

[9] Chen Zhi-He, Fang Hong-Wei and Liu Bin, "Numerical simulation of wind-induced motion in suspended sediment transport," Journal of Hydrodynamics, Ser. B, vol. 19, no. 6, pp. 698-704, 2007. DOI: $10.1016 / \mathrm{S} 1001-6058$ (08)60006-2.

[10] C. Koutitas and B. O'Connor, "Modeling threedimensional wind-induce flows," Journal of the Hydraulics Division, vol. 106, pp. 1843-1865, 1980.

[11] X. J. Lai, Q. Huang and J. H. Jiang, "Wetland inundation modeling of Dongting Lake using twodimensional hydrodynamic model on unstructured grids," Procedia Environmental Sciences, vol. 13, no. 3, pp. 1091-1098, 2012. DOI: 10.1016/j.proenv.2012.01.102.

[12] $\mathrm{Hu}$ Weiping, Pu Peimin and Qin Boqiang, “A Threedimensional numerical on the dynamics in Taihu Lake, China (I): the water level and the current during the 9711 Typhoon Process," Journal of Lake Sciences, vol. 10, no. 4, pp. 17-25, 1998

[13] Hu Weiping, Pu Peimin and Qin Boqiang, "A Threedimensional numerical on the dynamics in Taihu Lake, China (II): the typical wind-driven current and its divergence," Journal of Lake Sciences, vol. 10, no. 4, pp. 26-34, 1998.

[14] $\mathrm{Hu}$ Weiping, Qin Boqiang and Pu Peimin, "Threedimensional numerical experiments on hydrodynamics in Taihu Lake-3. Influence of the reclamation in Mashan district on wind-driven current," Journal of Lake Sciences, vol. 12, no. 4, pp. 335-342, 2000.

[15] HAN Hong-Juan, HU Wei-Ping and JIN Yi-Quan, "Numerical experiments on influence of wind speed on current in lake," Oceanologia et Limnologia Sinica, vol. 39, no. 6, pp. 567-576, 2008.

[16] HAN Hongjuan, HU WeiPing and JIN YiQuan, "Numerical experiments on the influences of inlet and outlet flow on lake current," Transactions of Oceanology and Limnology, no. z1, pp. 37-45, 2007.

[17] P. J. Roache, "Computation Fluid Dynamics," Mathematics of Computation, Albuquerque, 1976.

[18] Yang Zhi and Feng Minquan, "Hei river flood risk analysis based on coupling hydrodynamic simulation of 1-d and 2-d simulations," International Journal of Heat and Technology, vol. 33, no. 1, pp. 47-53, 2015. 
[19] Lv Suiju and Feng Minquan, "Three-dimensional numerical simulation of flow in Daliushu Reach of the Yellow River," International Journal of Heat and Technology, vol. 33, no. 1, pp. 107-114, 2015.

[20] A. Triki and E. Hadj-Taïeb," Numerical simulation for one dimensional open channel transient flow," International Information and Engineering Technology Association, vol. 26, pp. 87-94, 2008.

[21] Chen C. S., Hedong L. and Beardsley R. C., "An unstructured grid, finite-volume, three-dimensional, primitive equations ocean model: Application to coastal ocean and estuaries," Journal of Atmospheric and Oceanic Technology, vol. 20, no. 1, pp. 159-186, 2003. DOI: 10.1175/1520-0426 (2003)020.

[22] Chen C. S., Huang H. S., Beardsley R. C., et al., "A finite-volume numerical approach for coastal ocean studies: Comparisons with the finite-difference models," Journal of Geo-physical Research, vol. 112, no. C3, pp. 83-87, 2007. DOI: 10.1029/2006JC003485.

[23] Wang, J. H., Shen, Y. M. and Gou, Y. G, "Seasonal circulation and influence factors of the Bohai Sea: a numerical study based on Lagrangian particle tracking method," Ocean Dynamics, vol. 60, pp. 1581-1596, 2010. DOI: $10.1007 / \mathrm{s} 10236-010-0346-7$. 